\title{
PENERAPAN TEKNIK CETAK BIRU CYANOTYPE PADA BUSANA READY TO WEAR
}

\author{
APPLICATION OF CYANOTYPE BLUEPRINT TECHNIQUE \\ ON READY TO WEAR CLOTHING
}

\author{
Zumrotu Zakiyah ${ }^{1}$,Maya Komalasari ${ }^{*}$, Azria Nurafina ${ }^{1}$ \\ 1. Politeknik STTT, Bandung, 40272, Indonesia \\ *E-mail: mayakomala121@gmail.com
}

\begin{abstract}
ABSTRAK
Cyanotype, merupakan seni percetakan fotografi cetak biru. Proses ini merupakan proses memanfaatkan sensitivitas terhadap cahaya untuk membuat fotografi gambar atau fotogram di atas kertas atau kain. Cyanotype disebut juga dengan istilah blueprint berwarna biru / cyan. Penelitian ini dilakukan untuk busana fesyen. Inspirasi dari perancangan adalah botanica prussian gaya hippies. Ilustrasi botanica dijadikan motif sebagai warna dasar menggunakan teknik cetak biru/cyanotype dengan kalium ferricyanide atau hidrogen peroksida untuk proses fiksasinya. Motif botanica yang dipilih adalah motif dedaunan, dandelion serta bunga sepatu. Bunga dandelion memiliki arti kehidupan pantang menyerah dan bunga sepatu yang melambangkan kasih sayang, kemurnian, dan kebahagian.

Berdasarkan percobaan telah dilakukan penerapan motif botanica pada rancangan busana ready to wear dengan menerapkan teknik cetak biru cyanotype mulai proses pembuatan desain motif, persiapan emulsi cyanotype, proses sensitizing/ pengolesan emulsi pada media kain, pengeringan, proses penyinaran, pembilasan dan pengeringan hasil akhir kain. Implementasi gaya hippies pada bentuk motif botanica berupa dedaunan dan bunga dandelion yang dimodifikasi menjadi motif renggaan yang dipadukan dengan gambar tape kaset telah diaplikasikan pada busana ready to wear.
\end{abstract}

Kata kunci : Cyanotype, ready to wear, motif botanica, seni kontemporer

\begin{abstract}
Cyanotype, is the art of blueprint photographic printing. This process is utilizing sensitivity to light able to make photographic images or photographs on paper or cloth. Cyanotype is also known as blueprint in blue / cyan. This research was conducted for ready to wear fashion clothes. The inspiration for the design was prussian botanica influenced by the style of the hippies. The botanic illustration was used as a motif as the base color using a blueprint / cyanotype technique with potassium ferricyanide and hydrogen peroxide for the fixation process. The botanic motifs chosen were the leaves and dandelion motifs and the hibiscus flowers. The dandelion means an unyielding life and the shoe flower symbolizes affection, purity, and happiness.
\end{abstract}

Based on the experiment, the application of botanical motifs in ready-to-wear clothing designs has been carried out by applying the cyanotype blueprint technique starting from the process of making the motif design, preparing the cyanotype emulsion, 
sensitizing the emulsion process on fabric media, drying, irradiating, rinsing and drying the final fabric. The hippie style implementation of the botanica motif in the form of leaves and dandelion flowers which was modified into a renggaan motif combined with a cassette tape image has been applied to ready-to-wear clothing.

Keyword : Cyanotype, ready to wear, botanical motif contemporer art

\section{PENDAHULUAN}

Proses cetak biru Cyanotype merupakan salah satu jenis cetak fotografi old print yang memanfaatkan sensitivitas terhadap cahaya dalam proses cetaknya. Cyanotype ini tidak hanya dicetak pada media kertas, namun juga dapat dicetak pada kain, kayu, batu dan media lain (Irwandi, 2018). Pemakaian proses cetak Cyanotype pada dunia fesyen sangat kurang, hal ini dapat dipengaruhi oleh metode, proses ataupun kurangnya informasi untuk aplikasi penggunaannya, sehingga hal ini menjadi salah satu upaya bagaimana penerapan proses cetak Cyanotype di dunia fesyen. Proses cetak cyanotype adalah dengan menggunakan dua zat kimia larutan garam besi yaitu ferric amonium citrate, dan potassium ferricyanide, yang membentuk pigmen warna biru prusia. Kedua zat tersebut masing-masing dilarutkan dengan menggunakan air sampai menjadi larutan cyanotype yang berwana biru (Wells, K, 2015). Pengembangan penggunaan proses cetak cyanotype dapat dilihat pada Gambar 1 di bawah ini. 


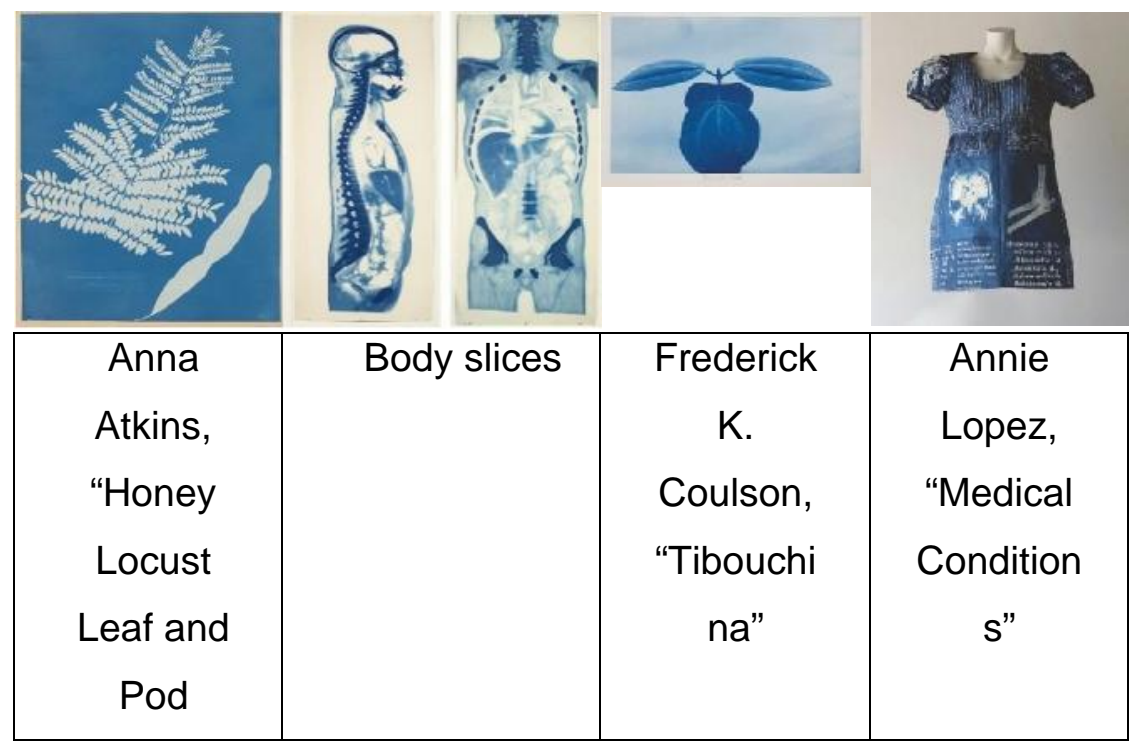

Sumber: https://hyperallergic.com

\section{Gambar 1. Pengembangan penggunaan proses cetak biru}

Pengembangan variasi motif

penggunaan proses cetak Cyanotype pada busana ready to wear pada penelitian ini didasari oleh flower generation dengan sumber inspirasi motif yaitu botanica prussian. llustrasi botanica diterapkan menjadi motif pada proses cetak Cyanotype untuk busana ready to wear dan prussian sebagai warna dasar yang dihasilkan dari zat kimia kalium ferricyanide pada proses Cyanotype (Syafi'udin, 2010). Gaya busana yang diangkat mengacu kepada trend forecasting Indonesia tahun 2019/2020 yaitu Singularity dengan subtema Svarga: Upskill Craft (kriya berkelas). Upskill Craft (kriya berkelas), merupakan sebuah peningkatan nilai dari hasil kriya yang dibuat menjadi seni kontemporer. (Linda, 2011),

Material kain pada perancangan busana ready to wear ini menggunakan kain dengan serat alam sebagai kain media cetak Cyanotype, material tersebut dipilih karena proses cyanotype pada serat alam menghasilkan motif yang jelas dan warna yang baik. Motif ini bisa menjadi alternatif desain teknik printing dengan teknik cetak biru cyanotype pada busana ready to wear. 


\section{METODA PENELITIAN}

Metode penelitian dilakukan dengan beberapa tahapan yaitu penelitian historis (penelitian terhadap keadaan, perkembangan, serta pengalaman yang terjadi pada masa lampau dan menimbang secara teliti validitas dari sumber sejarah), dilanjutkan dengan studi pustaka kemudian dilakukan percobaan. Beberapa eksplorasi dan eksperimen dilakukan dengan mencoba beberapa jenis material untuk penerapan cetak biru Cyanotype sehingga menghasilkan warna dan motif yang sesuai dengan kebutuhan desain busana. Gambar 2.1 berupa ilustrasi dan pemilihan motif.

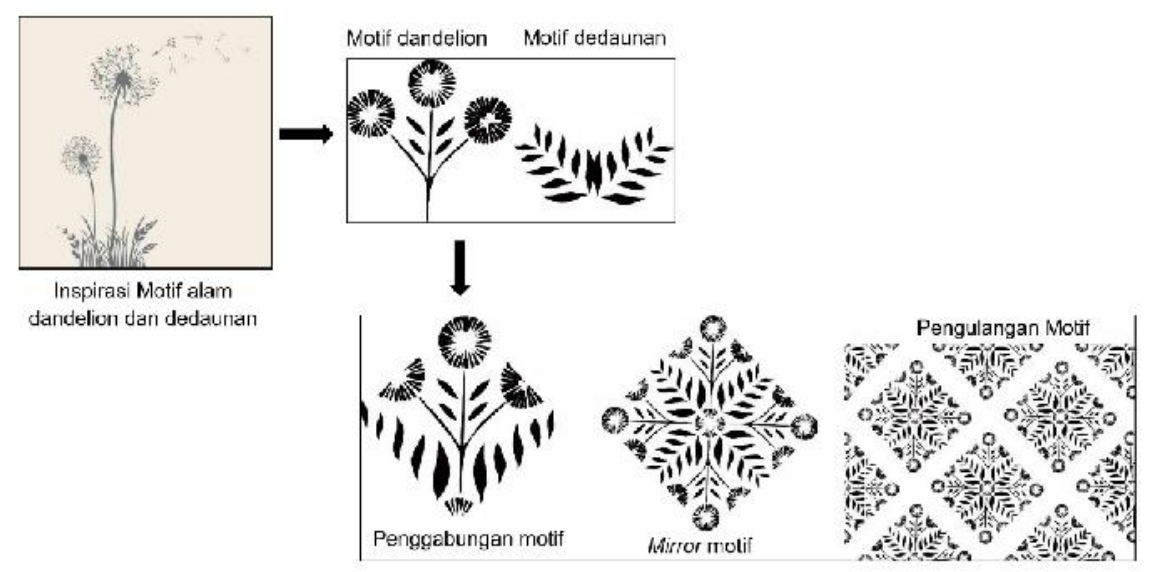

\section{Gambar 2.1 llustrasi dan pemilihan motif}

Berdasarkan ilustrasi gambar diatas, kemudian dibuat aplikasi desain menggunakan CoreIDRAW. Gambar
2.2 menunjukkan desain busana ready to wear dan proses pembuatan motif botanica menggunakan CoreIDRAW . 


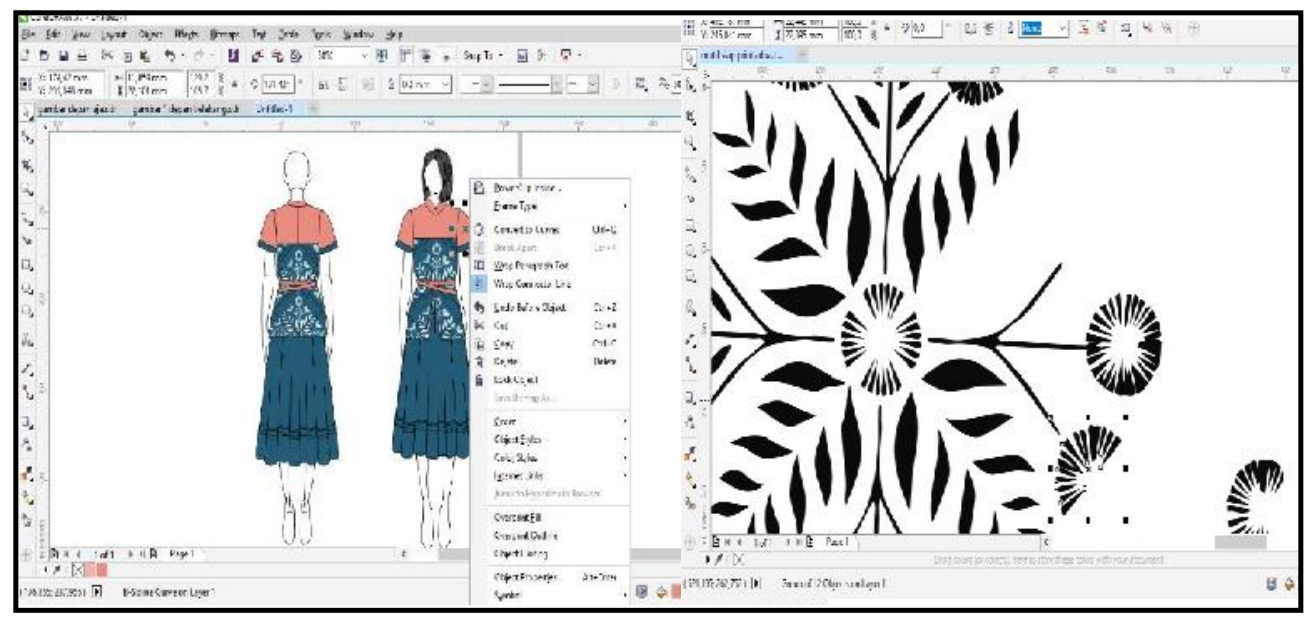

Gambar 2.2 Desain busana ready to wear dengan aplikasi coreldraw

\subsection{Alat dan Bahan}

2.1 Alat yang digunakan : busa, kertas kalkir, aquades, peralatan pembuatan pola, penggaris, penggaris siku, french curve, alat tulis, pita ukur, gunting, jarum, kertas pola, kapur jahit, mesin jahit jarum satu, mesin obras, pendedel.

2.2 Bahan: kain kapas, ferric amonium citrate, potassium ferricyanide dan hidrogen peroksida 3\%, zat yang digunakan berbahan teknis.

2.3 Pembuatan moodboard. Moodboard adalah media panduan desain, berisi kumpulan gambar, palet warna dan referensi sumber inspirasi lainnya. Moodboard yang digunakan dalam perancangan busana ready to wear dapat dilihat pada Gambar 2.3 di bawah ini. 


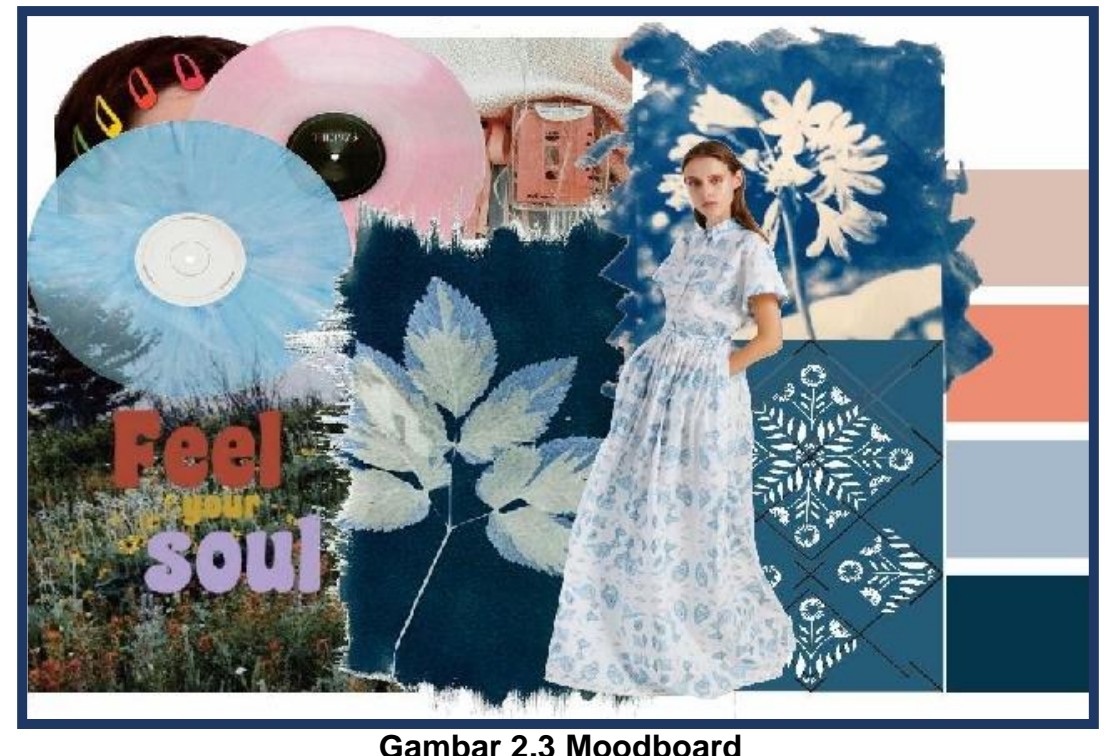

Gambar 2.3 Moodboard

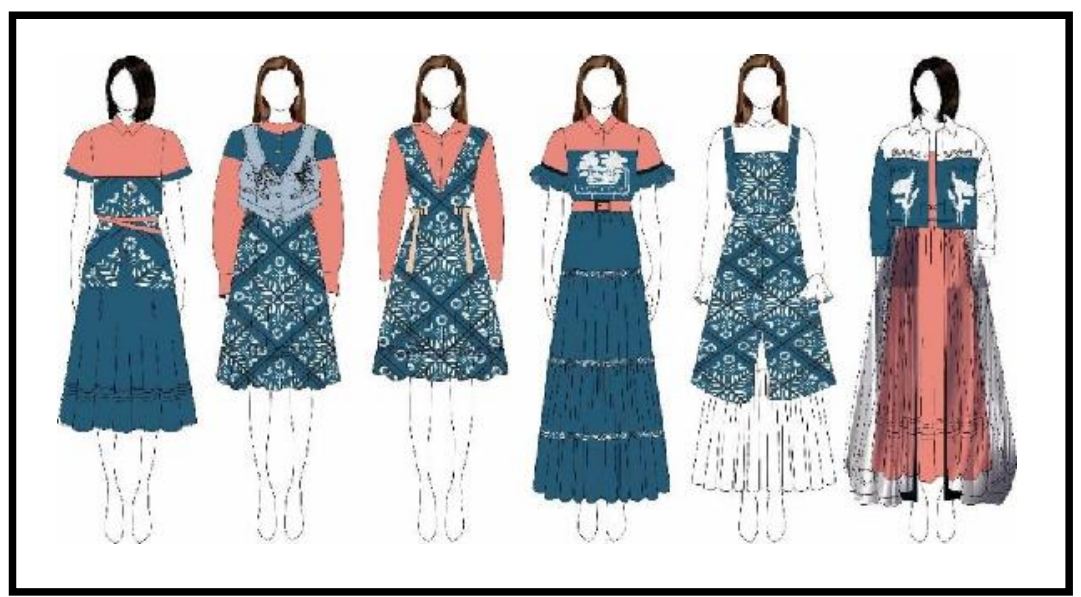

Gambar 2.4 Desain produk busana ready to wear 
Diagram alir pembuatan teknik cetak biru cyanotype dengan media kain dapat dilihat pada gambar 2.5 di bawah ini.

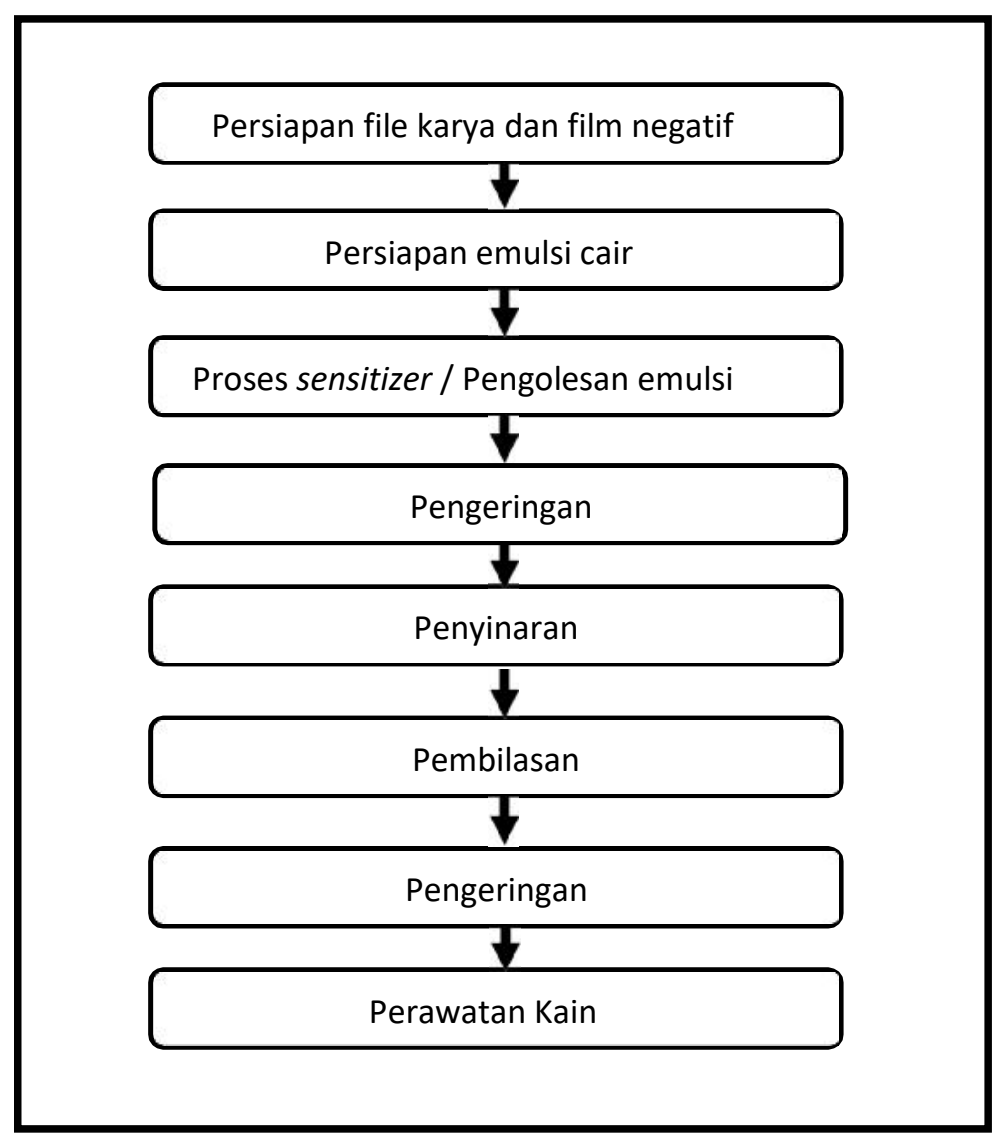

Gambar 2.5 Diagram alir proses cetak biru Cyanotype

\section{HASIL DAN PEMBAHASAN}

\subsection{Analisis Proses}

Berdasarkan analisa proses pada pembuatan ready to wear ini memiliki banyak aspek yang perlu diperhatikan. Aspek yang perlu diperhatikan yaitu aspek material, aspek cahaya dan juga aspek fiksasi warna sebagai berikut :

1. Aspek Material
Pada aspek ini adalah pemilihan jenis material kain mempengaruhi hasil akhir warna dan ketajaman motif dari hasil cetak cyanotype. Hal ini berkaitan dengan teori bahwa proses cetak cyanotype hanya dapat dilakukan pada jenis kain dengan serat alam. Pemilihan kain kapas selain nyaman dipakai karena mempunyai afinitas terhadap warna dari teknik cetak cyanotape (Irwandi, 2018). Gradasi warna yang 
dihasilkan oleh teknik cetak cyanotape lartan dan waktu proses cyanotape dapat dilihat di Gambar 3.1. Warna maka warna yang dihasilkan semakin hasil cetak cyanotape menunjukan tua.

bahwa semakin tinggi penggunaan

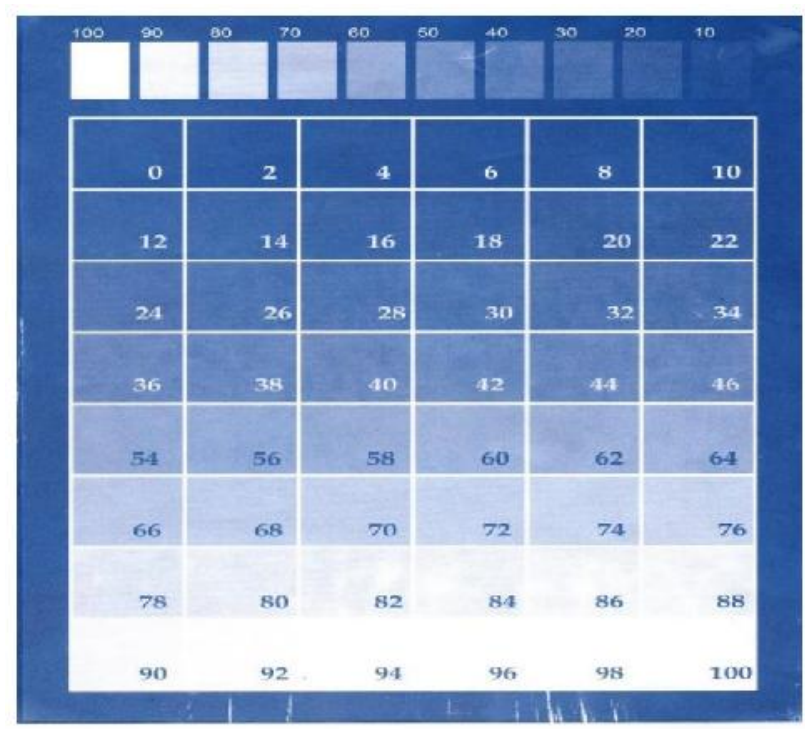

Sumber: 'Cyanotype and Anthotype: Ecopatterning with mineral and natural dyes.' Proceedings: International Textile \& Costume Congress. Wells, K. (2015),. Gambar 3.1 Warna hasil cetak cyanotype 


\section{Aspek Cahaya}

Cahaya sebagai sumber energi untuk memunculkan warna biru prusia pada proses cetak cyanotype ini. Waktu kontak kain yang beremulsi cyanotype dengan matahari dapat mempengaruhi hasil akhir warna yang dihasilkan proses cetak ini. Semakin sebentar kontak maka akan semakin pudar dan

\section{Aspek Fiksasi Warna}

Tujuan fiksasi adalah merekatkan zat warna terhadap kain. Kain hasil cetak cyanotype telah menghasilkan warna yang sesuai yaitu biru. Komposisi penggunaan ferric amonium citrate, dan kalium ferricyanide, yang membentuk pigmen warna biru prusia, sangat berpengaruh terhadap warna yang dihasilkan. Penambahan hidrogen peroksida yang ditambahkan juga berpengaruh terhadap kualitas warna. Perawatan garmen pada produk ini sangat disarankan untuk mencuci dengan cara dry clean.

\subsection{Analisis Produk}

Rancangan busana ready to wear ini diambil dari inspirasi Trend Forecasting 2019/2020 dengan sub tema Svarga yaitu upskill craft. Produk ini bias. Jika sinar yang diberikan tidak merata atau terhalang sebuah bayangan pada saat proses penyinaran maka dapat menghasilkan ketidakrataan warna ataupun jika disengaja ketidakrataannya dapat menghasilkan gradasi warna biru prusia

menggunakan penerapan teknik yang sama yaitu penerapan motif botanica yang dihasilkan dari memanfaatkan teknik cetak biru cyanotype yang merupakan teknik cetak fotografi peka cahaya pada setiap produk busana. Pembuatan motif botanica untuk proses cetak cyanotype dilakukan dengan menggunakan media software yaitu corelDraw pada komputer dalam bentuk digital. Desain motif yang telah dibuat dalam bentuk digital dicetak pada kertas kalkir untuk motif ukuran kecil dan stiker transparan pada motif yang berukuran besar. Pada motif berukuran besar stiker transparan ditempelkan pada kaca transparan yang menjadi bagian dari alat pembuatan teknik cetak cyanotype.

Pembuatan motif pada busana ready to wear ini menghasilkan motif botanica yaitu dedaunan, dandelion dan bunga sepatu dandelion yang memiliki arti kehidupan pantang menyerah dan bunga sepatu yang 
melambangkan kasih sayang, kemurnian, dan kebahagian. Kedua bunga ini juga mewakili arti dari sub tema svarga sebagai keindahan spritual dengan memodifikasi bentuk bunga menjadi bentuk renggaan yaitu memodifikasi bentuk alam menjadi bentuk baru dengan tidak menghilangkan bentuk aslinya. Bentuk baru yang dibuat adalah geometri terlihat seperti kain hasil pembatikan yang memberikan kesan tradisional dan eclectic. Produk dengan penerapan teknik cyanotype ini dalam hal perawatan hasil cetak kainnya harus dalam perawatan ekstra dan tidak dapat disamakan dengan pakaian ready to wear lainnya. Gambar produk busana ready to wear dapat dilihat pada Gambar 3.2 di bawah ini.

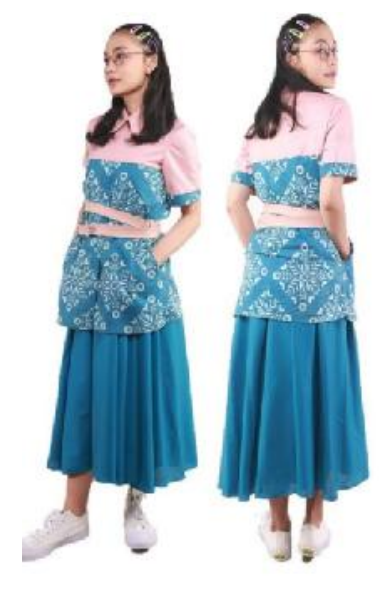

\section{KESIMPULAN}

1. Motif botanica pada rancangan busana ready to wear dilakukan dengan menerapkan teknik cetak biru cyanotype pada media kain. Cetak biru cyanotype menggunakan ferric amonium citrate atau potassium ferricyanide, yang membentuk pigmen warna biru prusia, dan hidrogen peroksida sebagai zat
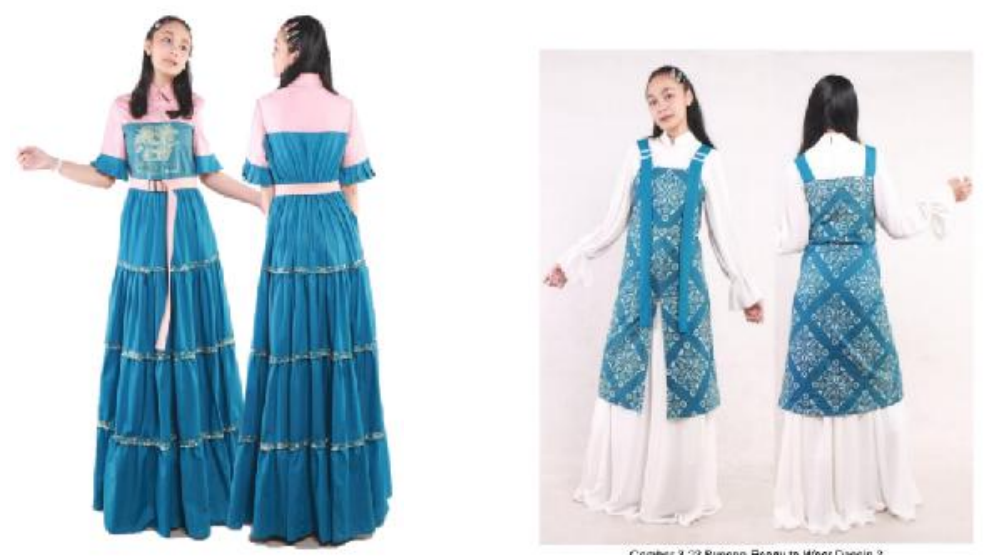

Gambar 3.2 Produk busana ready to wear 
botanica pada busana ready to

wear berupa dedaunan dan dandelion yang dimodifikasi

menjadi motif renggaan

diterapkan pada desain busana motif bunga sepatu yang dipadukan dengan gambar tape kaset telah diaplikasikan pada busana ready to wear.

\section{DAFTAR PUSTAKA}

1. Holtaschye, Linda. (2011), Understanding Color an Introduction for Designer (4 ${ }^{\text {th }}$ ed.) Fourthed. New J ersey: J hon Wiley \& Soms, Inc.

2. Irwandi. (2018), Reaktualisasi Teknologi Fotografi Abad Ke-19 dan 20 Studi Kasus pada Kelompok Kegiatan Mahasiswa KOPPI ISI Yogyakarta, Institut Seni Indonesia, Yogyakarta. Vol.14, No.1.

3. Kobayashi, Shigenobu. (1990). Color Image Scale. J epang: Kodansha Ltd.

4. Laury. (1997). Imagery On Fabric: a complete surface design handbook. China: C\&T Publishing, Inc..

5. Steele, Valerie. (2005). Encyclopedia of Clothing and Fashion. Drake Road: Thomson Gale.

6. Syafi'udin. (2010), CYANOTYPE : B lueprint Fotografi Alternatif. Institut Seni Indonesia. Denpasar.

7. Tim Penyusun Indonesia Trend Forecasting (ITF). (2019). SING ULARITY. J akarta: BEKRAF (Badan Ekonomi Kreatif Indonesia)

8. Wells, K. (2015), 'C yanotype and Anthotype: Ecopatterning with mineral and natural dyes.' Proceedings: International Textile \& Costume Congress. 2015. Between Worlds: Innovation and Design in Textiles and Costume. Marmara University, Istanbull

9. Welters.L.(2018), Fashion History: A Global View. B looms bury Academic.

10. https://www.beritaunik.net/unik-aneh/cerita-unik-tentang-kaum-hippiesamerika.html, diakses 01-07-2019 